\title{
Current endovascular strategies for cerebral venous thrombosis: report of the SNIS Standards and Guidelines Committee
}

\author{
Seon-Kyu Lee, ${ }^{1}$ Maxim Mokin, ${ }^{2}$ Steven W Hetts, ${ }^{3}$ Johanna T Fifi, ${ }^{4}$ \\ Marie-Germaine Bousser, ${ }^{5}$ Justin F Fraser, ${ }^{6}$ on behalf of the Society of \\ Neurolnterventional Surgery
}

- Additional material is published online only. To view please visit the journal online (http://dx.doi.org/10.1136/ neurintsurg-2018-013973).

'Department of Radiology, The University of Chicago, Chicago, Illinois, USA

${ }^{2}$ Department of Neurosurgery, University of South Florida

Tampa, Florida, USA ${ }^{3}$ Department of Radiology, UCSF, San Francisco, California, USA

${ }^{4}$ Department of Neurosurgery, Icahn School of Medicine at Mount Sinai, New York, USA ${ }^{5}$ Service de Neurologie, Hopital Lariboisiere, Paris, Île-de-France, France

${ }^{6}$ Department of Neurological Surgery, University of Kentucky, Lexington, Kentucky, USA

Correspondence to Dr Justin F Fraser, Departments of Neurological Surgery, Neurology, Radiology and Neuroscience, University of Kentucky, Lexington KY 40536, USA; Jfr235@uky.edu

Received 28 March 2018 Revised 27 April 2018 Accepted 1 May 2018 Published Online First 5 June 2018

Check for updates

To cite: Lee $S-K$, Mokin M Hetts SW, et al.

J Neurolntervent Surg

2018;10:803-810.

\section{INTRODUCTION}

Cerebral venous thrombosis (CVT) is a rare condition accounting for $<1 \%$ of all strokes, with highly variable clinical presentations ranging from a headache to coma. ${ }^{1-4}$ Although MRI and MR venography have significantly improved early diagnosis, clinical outcomes after treatment remain mixed. ${ }^{56}$

The aims of this document include: (1) to review existing knowledge about the natural history, diagnostic methodology, and treatment modalities/ techniques for CVT, and (2) to provide recommendations on management strategies for CVT using the best available evidence, but out of necessity, frequently relying on expert opinion concerning this rare disease. Recommendations follow the American College of Cardiology/American Heart Association (ACC/AHA) classification of recommendation/level of evidence and definition of classes and levels of evidence used in AHA/American Stroke Association (ASA) recommendations. ${ }^{7}$

\section{LITERATURE SEARCH}

The Standards and Guidelines Committee of the Society of Neurointerventional Surgery (SNIS), a multidisciplinary society representing leaders in the field of endovascular therapy for neurovascular disease, prepared this document based on a comprehensive review of English language literature relating to the topic. A literature search using PubMed (US National Library of Medicine) and Ovid (Wolters Kluwer) databases was performed from January 1, 1980, through December 31, 2016. The following key words were used: [(sinus thrombosis) AND ((cerebral veins) OR (cranial sinuses) OR (heparin) OR (thrombectomy) OR (anticoagulation))]. A review of references provided in review articles and textbook chapters was also performed. Studies published in languages other than English were excluded.

\section{Incidence/prevalence}

The estimated incidence of adult CVT is 1.32 per 100000 person-years. Among women aged between 31 and 50 years, the incidence is as high as 2.78 per 100000 person-years. ${ }^{89}$ In children less than 18 years of age, the estimated incidence is 0.67 per 100000 children per year, with neonates the most affected age group. ${ }^{10}$ Risk factors and conditions known to be associated with CVT are listed in table $1 .^{811}$ Inherited hypercoagulability including protein $\mathrm{C}$, protein $\mathrm{S}$, antithrombin deficiencies and factor V Leiden or resistance to activated protein C are estimated to account for $25-35 \%$ of all occurrences of CVT. ${ }^{12} 13$ The use of oral contraceptives is associated with a four- to sevenfold increase in the risk of CVT. ${ }^{14}$ In addition, the risk of CVT in woman using oral contraceptives may increase nearly 35 - fold if she is heterozygous for factor V Leiden. ${ }^{15}$ Around $15 \%$ of CVT cases occur in patients without identifiable risk factors or predisposing causes. ${ }^{8} 16$

\section{Natural history}

Data on the natural history of CVT are limited, as most studies reporting the clinical outcomes of CVT include patients treated with anticoagulation. ${ }^{17}$ Studies of the true natural history of CVT are available from the 'pre-heparin' era or from the placebo arms of the early randomized anticoagulation trials of CVT medical therapy. ${ }^{18-21}$ Outcomes of these studies are summarized in table 2. Mortality in the small populations of these studies ranged from $14 \%$ to $40 \%$ in patients who did not receive anticoagulation.

\section{DIAGNOSIS AND MANAGEMENT}

An algorithm for the diagnosis and management of CVT is shown in figure 1 .

\section{Clinical presentation}

Clinical presentations of CVT are diverse, and are affected by the patient's age, the interval between onset and hospitalization, location of thrombosis, and extent of the thrombosis. ${ }^{92}$ Common clinical signs and symptoms of CVT include headache, focal neurologic deficits, seizure, and diffuse encephalopathy, while rare symptoms include cavernous sinus syndrome and coma. ${ }^{4}$ Table 3 summarizes common presentations. The clinical significance and presentations of venous thrombosis depend on the location of the thrombosis and a patient's venous anatomical disposition, especially collateral pathways. Thus, clinical presentation can be diverse and non-specific. For example, CVT should be excluded before making the diagnosis of idiopathic intracranial hypertension since CVT can present with the insidious development of papilledema. ${ }^{23}$ Crescendo-type progression of non-specific clinical 
Table 1 Major risk factors and conditions associated with cerebral venous thrombosis

\begin{tabular}{|c|c|}
\hline Infection & $\begin{array}{l}\text { Paranasal sinusitis } \\
\text { Intracranial infections: abscess, meningitis }\end{array}$ \\
\hline Trauma & $\begin{array}{l}\text { Head trauma, neurosurgical operations } \\
\text { Internal jugular catheter }\end{array}$ \\
\hline $\begin{array}{l}\text { Medical/surgical } \\
\text { conditions }\end{array}$ & $\begin{array}{l}\text { Dehydration } \\
\text { Pregnancy and puerperium } \\
\text { Coagulation disorders: factor V Leiden, protein C } \\
\text { deficiency, protein S deficiency, antithrombin III deficiency, } \\
\text { hyperhomocysteinemia, antiphospholipid syndrome } \\
\text { Hematologic disorders: polycythemia, sickle cell disease, } \\
\text { thrombotic thrombocytopenic purpura, polycythemia, } \\
\text { paroxysmal nocturnal hemoglobinuria } \\
\text { Malignancies, inflammatory bowel disease, nephrotic syndrome, } \\
\text { liver cirrhosis, collagen vascular disease including systemic lupus } \\
\text { erythematosus, Wegener's granulomatosis and Behçet syndrome } \\
\text { Previous surgical procedures }\end{array}$ \\
\hline Medication & $\begin{array}{l}\text { Oral contraceptives, hormone replacement therapy, } \\
\text { L-asparagenase, corticosteroid }\end{array}$ \\
\hline
\end{tabular}

Modified from Lee SK et al. ${ }^{22}$

presentations such as seizure or focal neurological deficit over a few days should raise a strong suspicion, and be followed with appropriate imaging studies for the diagnosis of $\mathrm{CVT}^{22}$ Venous thromboembolism (deep vein thrombosis in the lower limbs or pulmonary embolism) may develop in patients with CVT.

\section{Diagnostic imaging}

CT

Neuroimaging findings of CVT are variable and multiple modalities may be required to assess both the venous vascular anatomy and parenchymal complications of edema, hemorrhage, and infarction. Non-contrast CT is non-specific and can be normal in up to $25 \%$ of patients. ${ }^{4}$ Classic signs of acute CVT
Table 2 Studies reporting natural history of venous sinus thrombosis

\begin{tabular}{|c|c|c|}
\hline Study & Description & Outcome, \% (n/N) \\
\hline Bousser et al ${ }^{19}$ & $\begin{array}{l}\text { Retrospective, single } \\
\text { center }\end{array}$ & $\begin{array}{l}\text { Death 27\% (4/15) } \\
\text { Deficits 20\% (3/15) }\end{array}$ \\
\hline de Bruijn et $a l^{20}$ & $\begin{array}{l}\text { Placebo arm, } \\
\text { randomized trial }\end{array}$ & $\begin{array}{l}\text { Death } 14 \%(4 / 29) \\
\text { Deficits with dependence } 10 \%(3 / 29)\end{array}$ \\
\hline Einhäupl et al ${ }^{18}$ & $\begin{array}{l}\text { Placebo arm, } \\
\text { randomized trial }\end{array}$ & $\begin{array}{l}\text { Death } 30 \%(3 / 10) \\
\text { Deficits 60\% (6/10) }\end{array}$ \\
\hline Maiti et $a l^{21}$ & $\begin{array}{l}\text { Placebo arm, } \\
\text { randomized trial }\end{array}$ & $\begin{array}{l}\text { Death } 40 \%(8 / 20) \\
\text { Deficits 35\% (7/20) }\end{array}$ \\
\hline
\end{tabular}

on non-contrast CT of the head include an increase in attenuation (hyperdensity) of the occluded sinuses or cortical veins and cerebral edema (figure 2A). ${ }^{24}$ Intracerebral hemorrhage occurs in $9-39 \%$ and can present as parenchymal, intraventricular or subarachnoid hemorrhage. ${ }^{26-28} \mathrm{~A}$ wide range of non-contrast CT accuracy in diagnosing CVT has been reported: $30-100 \%$ for sensitivity and $83-100 \%$ for specificity. On contrast-enhanced CT, the empty delta sign characterized by an intraluminal filling defect may indicate a thrombus within the superior sagittal sinus. ${ }^{29}$ The empty delta sign is present in $4-28 \%$ of cases of CVT. ${ }^{28-30}$ Hemoglobin and hematocrit levels correlate with CT attenuation in cerebral venous sinuses, and their high levels may mimic CVT in certain conditions such as polycythemia. ${ }^{31} 32$ Two studies separately confirmed a Hounsfield unit $>70$ to be highly specific for acute CVT. ${ }^{3133}$

\section{MRI}

The signal intensity of thrombus on MRI varies over time on T1- andT2-weighted sequences depending on the acuity of CVT (T1 isointensity and T2 hypointensity in the acute stage, and both $\mathrm{T} 1$ and $\mathrm{T} 2$ hyperintensity in the subacute stage; figure $2 \mathrm{~B}$, C). ${ }^{34}$ T2* gradient echo (GRE) and susceptibility weighted

\section{CVT is suspected}

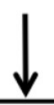

\begin{tabular}{|c|c|}
\hline \multirow{3}{*}{\multicolumn{2}{|c|}{ 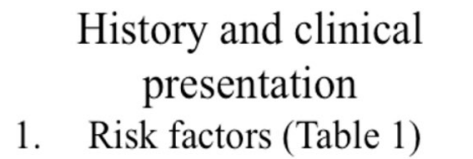 }} \\
\hline & \\
\hline & \\
\hline & Symptoms (Table 3) \\
\hline & Imaging \\
\hline & CT brain + CTV head/neck \\
\hline & MRI brain + MRV head/ \\
\hline & neck \\
\hline & $\begin{array}{l}\text { DSA if unable to determine } \\
\text { based on CT/MR alone }\end{array}$ \\
\hline
\end{tabular}

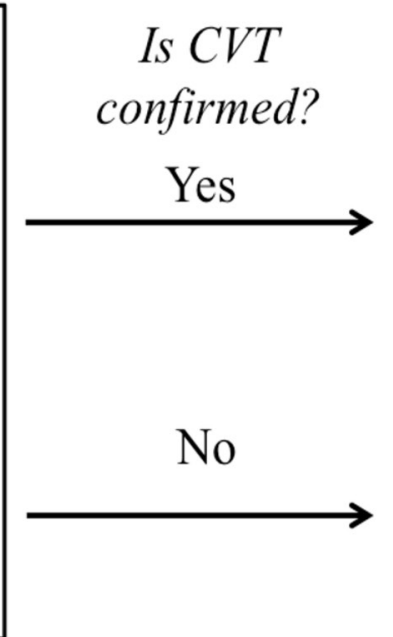

\section{Treatment}

1. Anticoagulation with UFH or LMWH

2. Endovascular treatment - indications:

- Clinical deterioration despite anticoagulation

- Contraindications to anticoagulation

- Coma

- Deep CVT

- ICH

3. Hemicraniectomy:

- Large lesions with herniation

4. Intracranial pressure monitoring

\section{Diagnosis and treatment of alternative conditions \\ Brain tumor, infection, ischemic stroke, PRES, idiopathic intracranial hypertension}

Figure 1 An algorithm for the diagnosis and management of CVT. CTV, CT venography; CVT, cerebral venous thrombosis; ICH, intracerebral hemorrhage; LMWH, low molecular weight heparin; MRV, magnetic resonance venography; PRES, posterior reversible encephalopathy syndrome; UHF, unfractionated heparin. 


\begin{tabular}{l}
\hline Table 3 Clinical presentations of cerebral venous thrombosis \\
\hline Symptoms \\
\hline Headache \\
\hline Double or blurred vision \\
Altered consciousness \\
\hline Seizure \\
\hline Behavioral symptoms (delirium, amnesia, mutism) \\
\hline Signs \\
\hline Papilledema \\
Focal neurologic deficit \\
Cranial nerve palsy \\
Nystagmus \\
\hline Modified from Lee SK, et al. ${ }^{22}$ \\
\hline
\end{tabular}

imaging (SWI) are highly accurate conventional MRI sequences in the diagnosis of CVT, owing to their sensitivity for susceptibility effects from hemorrhage/thrombus and blood oxygen level dependent imaging to delineate the venous anatomy, respectively. ${ }^{35}{ }^{36}$ Heterogeneous MRI patterns are also observed with diffusion-weighted imaging (DWI) and calculated apparent diffusion coefficient (ADC) mapping in the evaluation for venous infarction in the setting of CVT. ${ }^{37}$ Although vasogenic edema is characterized by an increase in ADC values and is reversible, persistent lesions with restricted diffusion (low ADC values) are suggestive of cytotoxic edema and infarction, but reversibility can be seen in patients with seizures. ${ }^{38}$ Venous infarction patterns on MRI differ from arterial territory stroke and are often bilateral, helping distinguish CVT from arterial etiologies. ${ }^{39}$ Conventional MRI sequences including T1-, T2-, T2*-weighted GRE, SWI, fluid-attenuated inversion recovery (FLAIR), and DWI are more accurate than non-contrast CT, and have an overall sensitivity of $72-84 \%$ and specificity of $90-95 \%$ for the diagnosis of CVT. ${ }^{39} 40$ Contrast-enhanced 3D GRE T1-weighted imaging with capability of multiplanar imaging is even more accurate than conventional MRI sequences in detecting CVT (93\% sensitivity and $100 \%$ specificity). ${ }^{40}$

\section{CT and MR venography}

Both CT venography (CTV) and MR venography (MRV) are highly accurate in diagnosing CVT when the two imaging modalities are compared directly with each other or with digital subtraction angiography (DSA). ${ }^{41-43}$ The choice of imaging is based on the assessment of the risk of ionizing radiation and
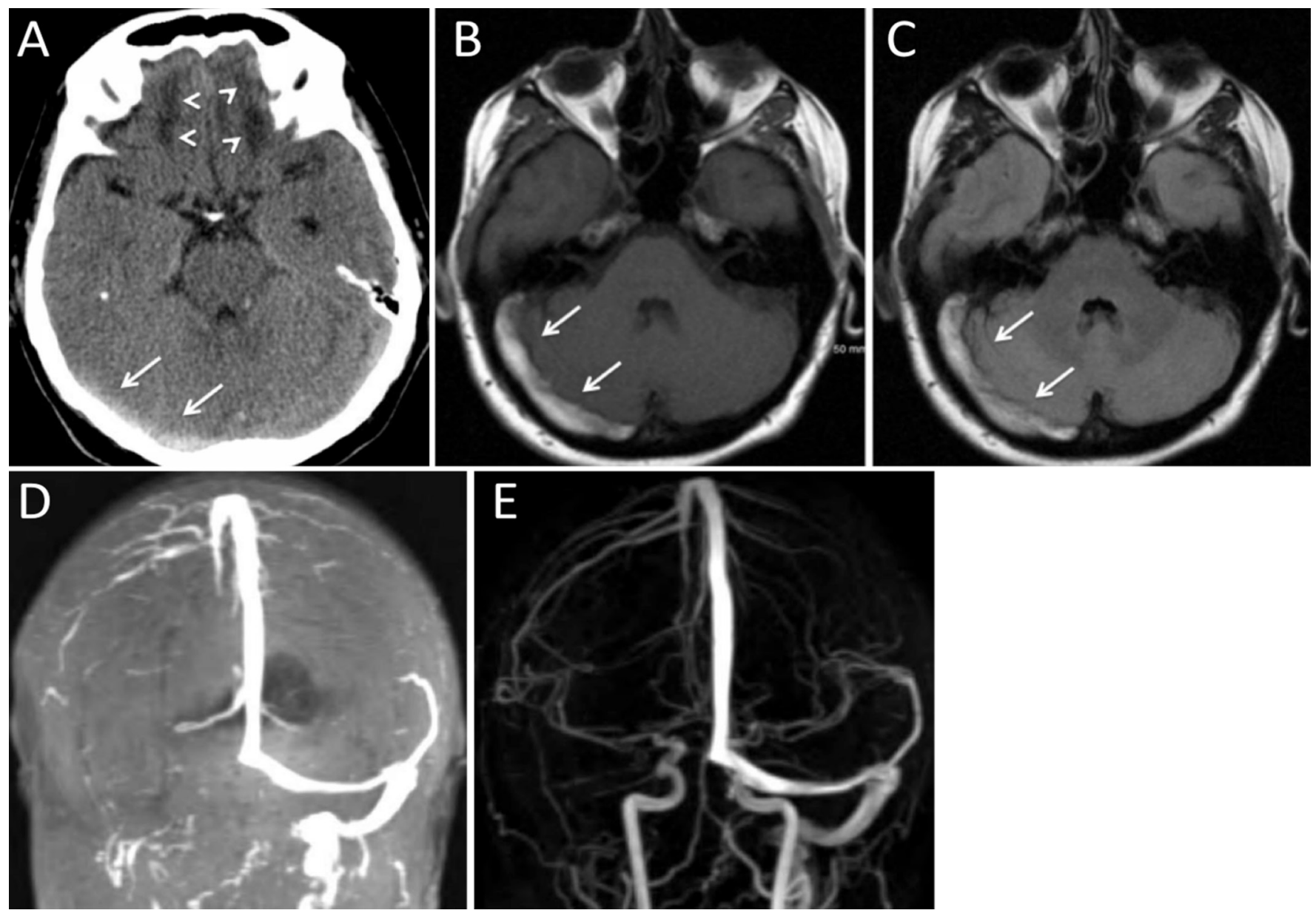

Figure 2 Right transverse sinus venous sinus thrombosis in a patient with head trauma. (A) Non-contrast CT of the head, axial view, shows a hyperintensity within the right transverse sinus (arrows) measuring $>70$ Hounsfield units, which is highly specific for acute thrombus. Bilateral frontal lobe hypodensities are consistent with the diagnosis of recent head trauma (arrowheads). (B) T1 and (C) FLAIR images of MRI brain performed 3 days after the initial head CT show an area of increased signal intensity within the right transverse sinus, consistent with subacute thrombus (arrows). (D) Time-of-flight MR venography and (E) contrast-enhanced MR venography demonstrate normal appearance of the superior sagittal sinus and left transverse sinus. No flow signal in the right transvers sinus and right internal jugular vein is seen. 
iodinated contrast required for CTV versus contraindications to MRI such as the presence of implantable devices or metallic foreign bodies. The estimated sensitivity and specificity of CTV in diagnosing CVT is $75-100 \% .{ }^{41}$ Two dimensional (2D) time-of-flight MRV does not require the use of gadolinium contrast. Depending on the plane of image acquisition, saturation and nulling of the venous signal can occur, leading to misdiagnosis of CVT with false-positive results for the extent of thrombus or failure to differentiate thrombus from dural sinus hypoplasia. ${ }^{4445}$ Three-dimensional (3D) contrast-enhanced MRV is better than time-of flight MRV with multiplanar imaging in providing consistent visibility of the venous anatomy including the large dural venous sinuses, deep venous system, and smaller cortical veins, resulting in improved accuracy in diagnosing CVT (figure 2D). ${ }^{44} 46$ The reported sensitivity and specificity of 3D contrast-enhanced MRV are $93 \%$ and $100 \%$, respectively. ${ }^{40}$

There are limited data on the value of perfusion imaging in the diagnosis and management of CVT. However, these studies are not included in the standard diagnostic imaging algorithm. Studies suggest that changes in cerebral blood flow and volume in CVT may be analogous to the 'core and penumbra' phenomenon in arterial ischemic stroke. ${ }^{4-49}$

\section{Digital subtraction angiography}

Digital subtraction angiography may show (1) non-visualization of dural sinus or cortical vein(s), (2) intraluminal filling defects, and (3) angiographic evidence of venous congestions such as engorgement of cortical veins, visualization of prominent medullary veins or reversal flow of cortical vein. In comparison with other non-invasive imaging methods, DSA can demonstrate both anatomical status and physiological response of each individual who develops CVT. The visualized physiological response, such as venous collateral pathways and altered venous phases of brain circulation, may explain, and provide some clues to, individual differences of patients with CVT. However, DSA has not been the main preferred modality for the diagnosis of CVT. ${ }^{22}$ Data from multicenter registries show that the imaging diagnosis of CVT is most commonly established with a combination of MRI and MRV (44-71\%), whereas catheter angiography is needed in only $12-21 \%$ of cases to help establish the diagnosis. ${ }^{28} 50$ With continued advancements in the non-invasive imaging of CVT, it is expected that the role of DSA as a diagnostic tool will further decline. Studies comparing the accuracy of non-invasive CTV with DSA in the diagnosis of CVT have suggested that conventional angiography may be especially helpful in cases of CVT involving the cavernous sinus and the smaller deep veins, such as the internal cerebral veins, thalamostriate veins, and the basal vein of Rosenthal. ${ }^{5152}$

\section{Medical and surgical treatment}

The goals of CVT management are to prevent the progression of venous thrombosis, re-establish venous flow, and manage underlying cause(s) of any prothrombotic state to prevent recurrence of CVT. Management of the underlying etiologies and prevention of CVT recurrence are beyond the scope of this document.

Systemic anticoagulation has been regarded as the firstline treatment, ${ }^{4-6}$ while surgical and neurointerventional procedures, such as ventriculostomy, decompressive surgery, intrasinus thrombolysis, and/or mechanical thrombectomy, are usually reserved for patients who do not respond to anticoagulation therapy. ${ }^{562253}$ However, in a multicenter prospective study (International Study on Cerebral Vein and Dural Sinus Thrombosis), even with anticoagulation therapy, about $13 \%$ of patients with CVT either died or were dependent. ${ }^{50}$ Thus, there is a clear need for further therapeutic advancement. Neurointerventional procedures such as thrombectomy might improve clinical outcomes while maintaining safety for a selected group of patients with CVT. ${ }^{1154-57}$

\section{Anticoagulation}

Two randomized controlled trials have investigated the efficacy of anticoagulation therapy. The first, a randomized, blinded placebo-controlled study in patients with aseptic dural sinus thrombosis using intravenous unfractionated heparin (UFH) was stopped after enrollment of the initial 20 patients because of a significant difference in outcome between the heparin and placebo group favoring UFH. ${ }^{18}$ In that trial, heparin was started with a 3000 IU intravenous bolus followed by continuous infusion until the initial partial thromboplastin time (PTT) doubled but did not exceed $120 \mathrm{~s}$, with a target PTT of $80-100 \mathrm{~s}$. The beneficial effects of heparin were seen after 3 days and up to 3 months. However, this trial was criticized for several reasons, including the small sample size and delayed enrollment into the study, which might have excluded severely ill patients and unvalidated outcome measurements employed in the study. ${ }^{58}$ The second trial compared subcutaneous nadroparin based on body weight versus placebo and demonstrated safety but failed to show statistically significant improvements in clinical outcomes. ${ }^{19}$ The nadroparin used in this trial was 180 anti-factor $\mathrm{Xa} \mathrm{IU} / \mathrm{kg}$ per 24 hours administered by two daily subcutaneous injections. A meta-analysis and systematic review of these two trials showed fewer dead or dependent patients with anticoagulation but failed to reach conventional statistical significance. ${ }^{69}$ Nevertheless, because of the relative safety of intravenous heparin therapy, and favorable statistical trends in the previous clinical trials, full anticoagulation remains first-line treatment for CVT regardless of the presence of intracerebral hemorrhage. ${ }^{60}$

There is no high level of evidence about which type of heparin results in a better clinical outcome in acute CVT. However, a systematic review of prior randomized trials and case series suggests that low molecular weight heparin is preferred over UFH. $^{596162}$ Regardless of anticoagulation therapy, coma, intracranial hemorrhage, and thrombosis of the deep cerebral venous system on admission were associated with unfavorable outcome. ${ }^{5063}$

\section{Intracranial pressure monitoring and management}

Transcranial Doppler imaging has been used to non-invasively estimate intracranial pressure (ICP) in CVT. ${ }^{64}$ However, there is also evidence that the pulsatility index that is used as a surrogate marker of ICP in this method may not be accurate.$^{65}$ Conflicting data exist for the role of external ventricular drainage or ventriculoperitoneal shunts in patients with CVT. ${ }^{667}$ These procedures can also be complicated by risks of anticoagulation.

\section{Hemicraniectomy}

Decompressive craniectomy and hematoma evacuation are typically reserved for patients with CVT with large parenchymal lesions causing herniation. ${ }^{68-70}$ Surgical intervention can result in a good functional outcome even in the most severe cases of CVT. ${ }^{69}{ }^{70}$ Early surgery (within 12 hours of admission), and younger patients are predictors of good outcome after decompressive craniectomy. ${ }^{68}$ There are no data to guide when to choose hemicraniectomy over endovascular management, or when and how to combine them in treating patients with severe thrombosis. 


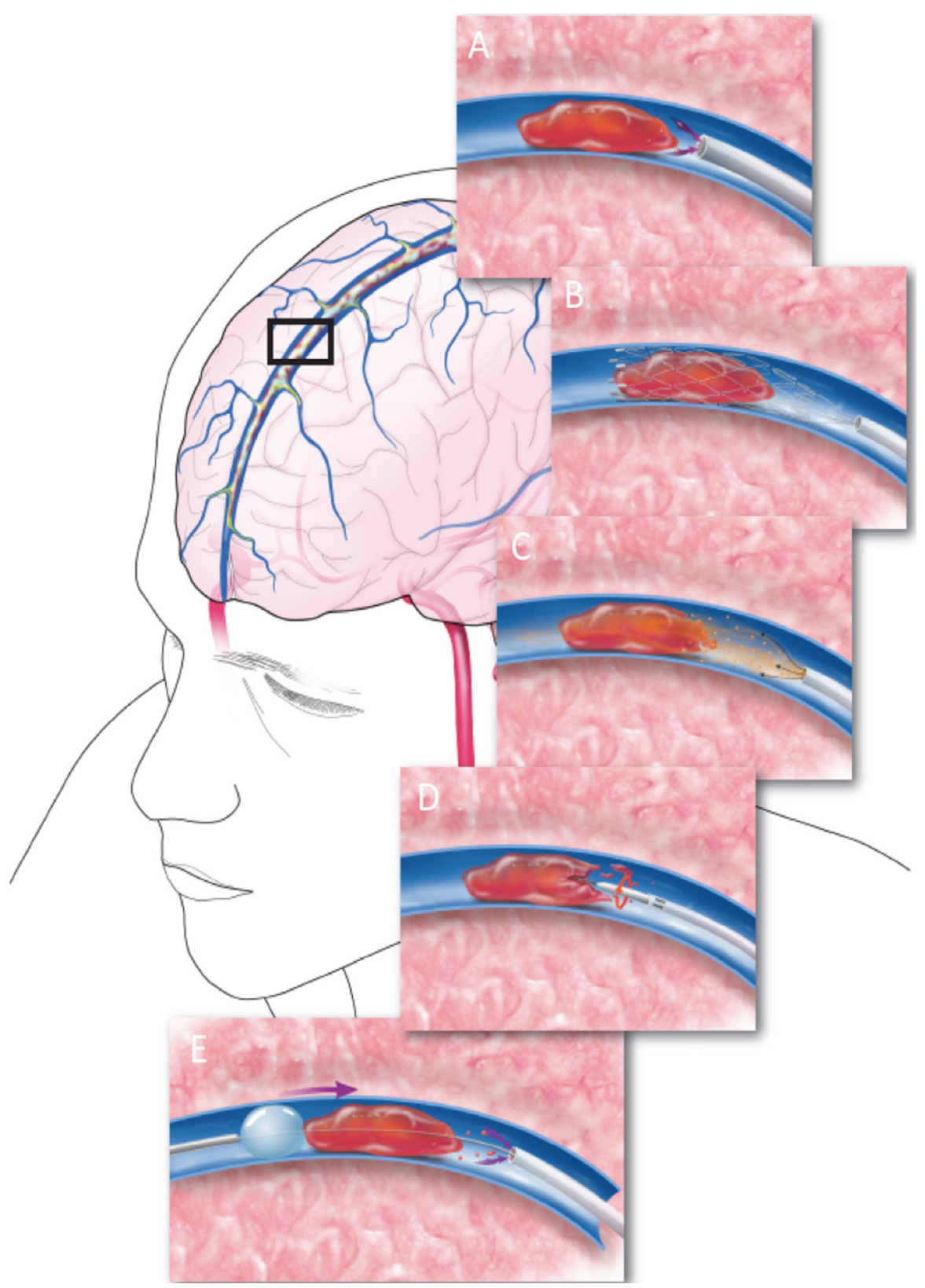

Figure 3 Illustration showing reported methods for venous sinus thrombectomy. These include (A) direct aspiration using an ADAPT technique, (B) mechanical thrombectomy with stent retrievers, (C) direct thrombolysis with local injection of thrombolytics, (D) clot disruption with Angiojet irrigation, (E) and mechanical suction with balloon-stabilized aspiration.

\section{ENDOVASCULAR MANAGEMENT Indications}

Neurointerventional procedures for CVT management are considered in patients with clinical deterioration or progression of intracerebral hemorrhage/venous infarction despite anticoagulation, severe stupor, comatose presentations, deep CVT, posterior fossa involvement or major contraindications to anticoagulation, such as bleeding disorders, thrombocytopenia $\left(<100 \times 10^{9} / \mathrm{L}\right)$, or recent GI hemorrhages. ${ }^{18} 2063$ However, exact indications for neurointerventional procedures require further validation. There is insufficient evidence to determine which approach and/or device provides the optimal restoration of venous outflow in CVT. ${ }^{71}{ }^{72}$ An illustration of the different approaches to endovascular therapy for CVT is shown in figure 3 .

\section{Procedural techniques}

Arterial and venous access

A 4 or 5 French arterial sheath is typically sufficient for arterial access to perform diagnostic cerebral angiography. The venous phase, including the delayed venous phase, can confirm the location and extent of sinus occlusion as well as venous collateral pathways. For femoral venous access, a $6 \mathrm{~F}$ long sheath will accommodate most thrombectomy devices, though a $7 \mathrm{~F}$ or $8 \mathrm{~F}$ sheath can be used to capture larger clot burdens with a larger catheter system. The guiding catheter or guide sheath is often placed in the internal jugular vein but if necessary can be delivered as far distally as the transverse sinus or torcular confluence. Also, an intermediate catheter can be used through the sheath, which can facilitate additional stability for endovascular devices. Direct access into the internal jugular vein provides alternative 
venous access, but access site thrombosis may compromise cerebral venous drainage if the contralateral jugular bulb is not adequate.

\section{Pharmacological thrombolysis}

Vines and Davis first performed intravenous pharmacological thrombolytic therapy for CVT using urokinase. ${ }^{73}$ Scott et al reported the first local urokinase infusion using an endovascular technique in $1988 .^{74}$ Since then, there have been many reports using various thrombolytic agents with excellent to good clinical outcome. ${ }^{75-81}$ In cases of extensive CVT, following local intrasinus delivery of an initial bolus of a thrombolytic agent, a microcatheter can be placed within the affected sinus for a continuous drip. Continuous intrasinus alteplase infusion can be delivered at the rate of $1-2 \mathrm{mg} /$ hour, and repeat angiography may be performed within 12-24 hours to measure the response to local thrombolysis to determine when discontinuation of such therapy is appropriate. ${ }^{82-83}$ The pharmacological thrombolysis technique can be combined with other thrombectomy techniques.

\section{Direct aspiration thrombectomy}

Analogous to arterial thrombectomy, large-bore distal aspiration catheters are now increasingly used for direct thrombus aspiration in CVT. ${ }^{84}$ This approach may be used alone or in conjunction with stent retriever thrombectomy. ${ }^{72}$ 85-86

\section{Stent retriever thrombectomy}

A variety of approaches to stent retriever thrombectomy combined with other endovascular modalities have been reported. A stent retriever may be used alone as treatment or in combination with local pharmacological thrombolysis. ${ }^{87-88} \mathrm{~A}$ stent retriever may also be used as an anchor while the distal access (aspiration) catheter is passed back and forth to aspirate the thrombus. ${ }^{89}$ Alternatively, a stent retriever and thrombus are removed into the aspiration catheter or as a unit into the large proximal guide sheath under ongoing continuous aspiration. ${ }^{90}$ This allows the thrombus to be captured by both aspiration and stent retriever devices.

\section{Balloon thrombectomy}

In this approach, a balloon is placed past the thrombus within the affected sinus/sinuses, inflated and retracted back toward the aspiration or guide sheath. This approach can be further combined with local pharmacological thrombolysis for effective removal and to prevent large pulmonary emboli. Fogarty 3 or $4 \mathrm{~F}$ balloon catheters are ideal to match the larger size of the dural sinuses for effective and efficient thrombectomy, but other lower profile, compliant and semicompliant neurovascular balloon microcatheters have also been successfully used for this approach. ${ }^{91} 92$

\section{Balloon angioplasty and stenting}

Angioplasty and stenting are used as rescue therapy when other more traditional modes of thrombectomy fail. ${ }^{93}$ Angioplasty/ stenting as a first-line endovascular treatment of CVT has not been evaluated.

\section{AngioJet}

AngioJet (MEDRAD Inc, Warrendale, Pennsylvania, USA) uses hydrodynamic thrombolytic action through high-velocity saline jets. ${ }^{94}$ The aspiration force draws the thrombus debris to the catheter inflow zone where it is evacuated from the body through the catheter.

Owing to the stiffness and bulkiness od the AngioJet, many operators have used the device for the initial partial recanalization of thrombosed dural venous sinuses. In a systematic review of 185 cases of CVT treated with mechanical thrombectomy, AngioJet use was associated with lower rates of complete recanalization and a lower chance of good outcomes than the use of other thrombectomy devices. ${ }^{56}$

\section{Periprocedural details}

In nearly all patients with CVT systemic heparinization will be initiated before the start of the endovascular thrombectomy thus requiring serial activated clotting time (ACT) measurements and adjustment of bolus doses of systemic heparin in the angiography suite. Intravenous heparin is administered to achieve an ACT of 250-300s during endovascular therapy. Effective anticoagulation is essential for procedural success in patients undergoing interventional therapy, and adequate postprocedural anticoagulation is important for preventing re-occlusion postoperatively.

\section{Goals of endovascular therapy}

Recanalization, either complete or partial, is associated with improved outcomes of CVT in comparison with patients with no recanalization, although the quality of data is limited by the small sample sizes in the studies that reported such an association. ${ }^{95-96}$ The goal of endovascular therapy is to re-establish anterograde venous outflow in the targeted sinus(es) to alleviate malignant venous congestion/hypertension and prevent its associated complications.

\section{SUMMARY OF RECOMMENDATIONS \\ Imaging}

- A combination of MRI/MRV or CT/CTV studies should be performed in patients with suspected CVT (class I; level of evidence $\mathrm{C}$ ).

- DSA as a diagnostic modality is indicated in cases of suspected CVT when the diagnosis of CVT cannot be reliably established with non-invasive imaging alone (class IIa; level of evidence C).

\section{Medical and surgical treatment}

- Anticoagulation with unfractionated heparin or low molecular weight heparin is reasonable in patients with CVT (class IIa; level of evidence C).

- Decompressive craniectomy may be considered in patients with large parenchymal lesions causing herniation or intractable intracranial hypertension (class IIb; level of evidence $\mathrm{C}$ ).

\section{Endovascular therapy}

- Endovascular therapy may be considered in patients with clinical deterioration despite anticoagulation, or with severe neurological deficits or coma (class IIb; level of evidence C). The duration of anticoagulation therapy before declaring it to be a 'failure' and proceeding with endovascular therapy is unknown.

- There is insufficient evidence to determine which endovascular approach and device provides the optimal restoration of venous outflow in CVT. In many cases, a variety of treatment approaches is required to establish sinus patency. 
Acknowledgements We would like to acknowledge the contribution of Tom Dolan in providing the medical illustration for Figure 2

Collaborators T Abruzzo, B Albani, SA Ansari, AS Arthur, M Bain, B Baxter, KR Bulsara, M Chen, G Dabus, D Frei, CD Gandhi, MS Hussain, MV Jayaraman, Y Kayan, RP Klucznik, T Leslie-Mazwi, WJ Mack, RA McTaggart, PM Meyers, J Mocco, AT Patsalides, CJ Prestigiacomo, GL Pride, Jr, RM Starke, PJ Sunenshine.

Contributors S-KL was the primary author and was responsible for overseeing construction of the document outline, gathering of evidence, and drafting of the manuscript. He also contacted our guest author (MGB) as a topic expert, and sough her input. MM made major contributions to the manuscript draft, and supplemented entire sections of the text. He also participated in discussions about the outline and organization of the text. SWH provided review and additional text to the manuscript. JTF acted as a representative of the Board of the Society of Neurolnterventional Surgery, and provided commentary and editing on behalf of the Board and of the Society as a whole. MGB was the invited topic expert, whose knowledge and experience in venous thrombosis disease provided vital international perspective. JFF, as senior author, was responsible for organizing the writing group, overseeing the outline construction, facilitating communication between the writing group and the Standards and Guidelines Committee, drafting and editing of the manuscript, and submission/proofing for publication.

Funding The authors have not declared a specific grant for this research from any funding agency in the public, commercial or not-for-profit sectors.

Disclaimer This literature review ("Review") is provided for informational and educational purposes only. Adherence to any recommendations included in this review will not ensure successful treatment in every situation. Furthermore, the recommendations contained in this review should not be interpreted as setting a standard of care, or be deemed inclusive of all proper methods of care or exclusive of other methods of care reasonably directed to obtaining the same results. The ultimate judgment about the propriety of any specific therapy must be made by the physician and the patient in light of all the circumstances presented by the individua patient, and the known variability and biological behavior of the medical condition. This review and its conclusions and recommendations reflect the best available information at the time it was prepared. The results of future studies may require revisions to the recommendations to reflect new data. SNIS does not guarantee the accuracy or completeness of the review and assumes no responsibility for anyinjury or damage to people or property arising out of, or related to, any use of this review or for any errors or omissions.

Competing interests JFF is an equity interest holder for Fawkes Biotechnology, LLC, and a consultant for Stream Biomedical. SWH is a consultant for Medina and Neuravi, and has research contracts with Stryker Neurovascular, Siemens, MicroVention Terumo. JTF has research grants from Stryker and Microvention, equity interest in Endostream, Cerebrotech, and The Stroke Project, and has consulted for Stryker and Penumbra. MM is a consultant for Toshiba (Canon) Medical. All other authors report no relevant conflicts of interest.

Patient consent Not required.

Provenance and peer review Not commissioned; externally peer reviewed.

(c) Article author(s) (or their employer(s) unless otherwise stated in the text of the article) 2018. All rights reserved. No commercial use is permitted unless otherwise expressly granted.

\section{REFERENCES}

1 Cantú C, Barinagarrementeria F. Cerebral venous thrombosis associated with pregnancy and puerperium. Review of 67 cases. Stroke 1993;24:1880-4.

2 Daif A, Awada A, al-Rajeh $\mathrm{S}$, et al. Cerebral venous thrombosis in adults. A study of 40 cases from Saudi Arabia. Stroke 1995:26:1193-5.

3 Kashyap AS, Anand KP, Kashyap S. Thrombosis of the cerebral veins and sinuses. N Engl J Med 2005;353:314-5.

4 Bousser MG, Ferro JM. Cerebral venous thrombosis: an update. Lancet Neurol 2007;6:162-70.

5 Ameri A, Bousser MG. Cerebral venous thrombosis. Neurol Clin 1992;10:87-111.

6 Benamer HT, Bone I. Cerebral venous thrombosis: anticoagulants or thrombolyic therapy? J Neurol Neurosurg Psychiatry 2000;69:427-30.

7 Morrison LJ, Gent LM, Lang E, et al. Part 2: Evidence evaluation and management of conflicts if Interest: 2015 American Heart Association Guidelines Update for Cardiopulmonary Resuscitation and Emergency Cardiovascular Care. Circulation 2015;132(18 Suppl 2):S368-82.

8 Ferro JM, Correia M, Pontes C, et al. Cerebral vein and dural sinus thrombosis in Portugal: 1980-1998. Cerebrovasc Dis 2001;11:177-82.

9 Coutinho JM, Zuurbier SM, Aramideh M, et al. The incidence of cerebral venous thrombosis: a cross-sectional study. Stroke 2012;43:3375-7.

10 deVeber $\mathrm{G}$, Andrew M, Adams C, et al. Cerebral sinovenous thrombosis in children. $N$ Engl J Med 2001;345:417-23.
11 Stam J, Majoie CB, van Delden OM, et al. Endovascular thrombectomy and thrombolysis for severe cerebral sinus thrombosis: a prospective study. Stroke 2008;39:1487-90.

12 Rosendaal FR. Thrombosis in the young: epidemiology and risk factors. A focus on venous thrombosis. Thromb Haemost 1997;78:1-6.

13 de Visser MC, Rosendaal FR, Bertina RM. A reduced sensitivity for activated protein $C$ in the absence of factor $V$ Leiden increases the risk of venous thrombosis. Blood 1999:93:1271-6.

14 Vandenbroucke JP, Rosing J, Bloemenkamp KW, et al. Oral contraceptives and the risk of venous thrombosis. N Eng/ J Med 2001;344:1527-35.

15 Vandenbroucke JP, Koster T, Briët E, et al. Increased risk of venous thrombosis in oral-contraceptive users who are carriers of factor $\mathrm{V}$ Leiden mutation. Lancet 1994:344:1453-7.

16 Masuhr F, Mehraein S, Einhäupl K. Cerebral venous and sinus thrombosis. J Neurol 2004;251:11-23.

17 Dentali F, Gianni M, Crowther MA, et al. Natural history of cerebral vein thrombosis: a systematic review. Blood 2006;108:1129-34.

18 Einhäupl KM, Villringer A, Meister W, et al. Heparin treatment in sinus venous thrombosis. Lancet 1991;338:597-600.

19 Bousser MG, Chiras J, Bories J, et al. Cerebral venous thrombosis--a review of 38 cases. Stroke 1985;16:199-213.

20 de Bruijn SF, Stam J, Randomized SJ. Randomized, placebo-controlled trial of anticoagulant treatment with low-molecular-weight heparin for cerebral sinus thrombosis. Stroke 1999:30:484-8.

21 Maiti B, Chakrabarti I. 3-07-24 Study on cerebral venous thrombosis with special reference to efficacy of heparin. J Neurol Sci 1997;150:S147.

22 Lee SK, Kim BS, Terbrugge KG, et al. Imaging and treatment of cerebral venous thrombosis (CVT). Interv Neuroradiol 2002:8:5-14.

23 Thorell SE, Parry-Jones AR, Punter M, et al. Cerebral venous thrombosis-a primer for the haematologist. Blood Rev 2015:29:45-50.

24 Ford K, Sarwar M. Computed tomography of dural sinus thrombosis. AJNR Am J Neuroradiol 1981:2:539-43.

25 Rao KC, Knipp HC, Wagner EJ. Computed tomographic findings in cerebral sinus and venous thrombosis. Radiology 1981;140:391-8.

26 Girot M, Ferro JM, Canhão P, et al. Predictors of outcome in patients with cerebral venous thrombosis and intracerebral hemorrhage. Stroke 2007;38:337-42.

27 Kalita J, Bansal V, Misra UK, et al. Intracerebral haemorrhage due to cerebral venous sinus thrombosis. QJM 2008;101:247-9.

28 Wasay M, Bakshi R, Bobustuc G, et al. Cerebral venous thrombosis: analysis of a multicenter cohort from the United States. I Stroke Cerebrovasc Dis 2008;17:49-54.

29 Virapongse C, Cazenave C, Quisling R, et al. The empty delta sign: frequency and significance in 76 cases of dural sinus thrombosis. Radiology 1987;162:779-85.

30 Rizzo L, Crasto SG, Rudà R, et al. Cerebral venous thrombosis: role of CT, MRI and MRA in the emergency setting. Radiol Med 2010;115:313-25.

31 Black DF, Rad AE, Gray LA, et al. Cerebral venous sinus density on noncontrast CT correlates with hematocrit. AJNR Am J Neuroradiol 2011:32:1354-7.

32 Healy JF, Nichols C. Polycythemia mimicking venous sinus thrombosis. AJNR Am J Neuroradiol 2002:23:1402-3.

33 Garetier M, Rousset J, Pearson E, et al. Value of spontaneous hyperdensity of cerebral venous thrombosis on helical CT. Acta Radiol 2014:55:1245-52.

34 Boukobza M, Crassard I, Bousser MG, et al. MR imaging features of isolated cortical vein thrombosis: diagnosis and follow-up. AJNR Am J Neuroradiol 2009;30:344-8.

35 Fellner FA, Fellner C, Aichner FT, et al. Importance of $\mathrm{T} 2^{*}$-weighted gradient-echo MRI for diagnosis of cortical vein thrombosis. Eur J Radiol 2005;56:235-9.

36 Selim M, Fink J, Linfante I, et al. Diagnosis of cerebral venous thrombosis with echoplanar T2*-weighted magnetic resonance imaging. Arch Neurol 2002;59:1021-6.

37 Ducreux D, Oppenheim C, Vandamme X, et al. Diffusion-weighted imaging patterns of brain damage associated with cerebral venous thrombosis. AJNR Am I Neuroradiol 2001:22:261-8.

38 Mullins ME, Grant PE, Wang B, et al. Parenchymal abnormalities associated with cerebral venous sinus thrombosis: assessment with diffusion-weighted MR imaging. AJNR Am J Neuroradiol 2004;25:1666-75.

39 Patel D, Machnowska M, Symons S, et al. Diagnostic performance of routine brain MRI sequences for dural venous sinus thrombosis. AJNR Am I Neuroradiol 2016.

40 Sari S, Verim S, Hamcan S, et al. MRI diagnosis of dural sinus - cortical venous thrombosis: immediate post-contrast 3D GRE T1-weighted imaging versus unenhanced MR venography and conventional MR sequences. Clin Neurol Neurosurg 2015;134:44-54

41 Khandelwal N, Agarwal A, Kochhar R, et al. Comparison of CT venography with MR venography in cerebral sinovenous thrombosis. AJR Am J Roentgenol 2006; 187:1637-43.

42 Ozsvath RR, Casey SO, Lustrin ES, et al. Cerebral venography: comparison of CT and MR projection venography. AJR Am J Roentgenol 1997;169:1699-707.

43 Rodallec MH, Krainik A, Feydy A, et al. Cerebral venous thrombosis and multidetector CT angiography: tips and tricks. Radiographics 2006;26 Suppl 1:S5-18.

44 Farb RI, Scott JN, Willinsky RA, et al. Intracranial venous system: gadolinium-enhanced three-dimensional MR venography with auto-triggered elliptic centric-ordered sequence--initial experience. Radiology 2003;226:203-9. 
45 Leach JL, Fortuna RB, Jones BV, et al. Imaging of cerebral venous thrombosis: current techniques, spectrum of findings, and diagnostic pitfalls. Radiographics 2006;26 Suppl 1:S19-41.

$46 \mathrm{Fu} \mathrm{JH}$, Lai PH, Hsiao CC, et al. Comparison of real-time three-dimensional gadolinium-enhanced elliptic centric-ordered MR venography and two-dimensional time-of-flight MR venography of the intracranial venous system. J Chin Med Assoc 2010;73:131-8

47 Doege CA, Tavakolian R, Kerskens CM, et al. Perfusion and diffusion magnetic resonance imaging in human cerebral venous thrombosis. J Neurol 2001;248:564-71.

48 Gupta RK, Bapuraj JR, Khandelwal N, et al. Prognostic indices for cerebral venous thrombosis on CT perfusion: a prospective study. Eur J Radio/ 2014;83:185-90.

49 Mokin M, Ciambella CC, Masud MW, et al. Whole-brain computed tomographic perfusion imaging in acute cerebral venous sinus thrombosis. Interv Neurol 2016;4(34):104-12.

50 Ferro JM, Canhão P, Stam J, et al. Prognosis of cerebral vein and dural sinus thrombosis: results of the International Study on Cerebral Vein and Dural Sinus Thrombosis (ISCVT). Stroke 2004;35:664-70.

51 Linn J, Ertl-Wagner B, Seelos KC, et al. Diagnostic value of multidetector-row CT angiography in the evaluation of thrombosis of the cerebral venous sinuses. AJNR Am J Neuroradiol 2007;28:946-52.

52 Wetzel SG, Kirsch E, Stock KW, et al. Cerebral veins: comparative study of CT venography with intraarterial digital subtraction angiography. AJNR Am J Neuroradiol 1999;20:249-55.

53 Stam J. Thrombosis of the cerebral veins and sinuses. N Engl J Med 2005;352:1791-8.

54 Gurley MB, King TS, Tsai FY. Sigmoid sinus thrombosis associated with internal jugular venous occlusion: direct thrombolytic treatment. J Endovasc Surg 1996;3 306-14.

55 Li G, Zeng X, Hussain M, et al. Safety and validity of mechanical thrombectomy and thrombolysis on severe cerebral venous sinus thrombosis. Neurosurgery $2013 ; 72: 730-8$

56 Siddiqui FM, Dandapat S, Banerjee C, et al. Mechanical thrombectomy in cerebral venous thrombosis: systematic review of 185 cases. Stroke 2015;46:1263-8.

57 Diaz JM, Schiffman JS, Urban ES, et al. Superior sagittal sinus thrombosis and pulmonary embolism: a syndrome rediscovered. Acta Neurol Scand 1992;86:390-6.

58 Stam J, Lensing AW, Vermeulen $M$, et al. Heparin treatment for cerebral venous and sinus thrombosis. Lancet 1991;338:1154.

59 Coutinho J, de Bruijn SF, Deveber G, et al. Anticoagulation for cerebral venous sinus thrombosis. Cochrane Database Syst Rev 2011;8:CD002005.

60 Bousser MG. Cerebral venous thrombosis: nothing, heparin, or local thrombolysis? Stroke 1999:30:481-3.

61 Coutinho JM, Seelig R, Bousser MG, et al. Treatment variations in cerebral venous thrombosis: an international survey. Cerebrovasc Dis 2011;32:298-300.

62 Misra UK, Kalita J, Chandra S, et al. Low molecular weight heparin versus unfractionated heparin in cerebral venous sinus thrombosis: a randomized controlled trial. Eur J Neurol 2012;19:1030-6.

63 Canhão P, Ferro JM, Lindgren AG, et al. Causes and predictors of death in cerebral venous thrombosis. Stroke 2005;36:1720-5.

64 Wakerley B, Yohana K, Luen Teoh H, et al. Non-invasive intracranial pressure monitoring with transcranial Doppler in a patient with progressive cerebral venous sinus thrombosis. J Neuroimaging 2014;24:302-4.

65 Behrens A, Lenfeldt N, Ambarki K, et al. Transcranial Doppler pulsatility index: not an accurate method to assess intracranial pressure. Neurosurgery 2010;66:1050-7.

66 Lobo S, Ferro JM, Barinagarrementeria F, et al. Shunting in acute cerebral venous thrombosis: a systematic review. Cerebrovasc Dis 2014;37:38-42.

67 Torikoshi S, Akiyama Y. Report of dramatic improvement after a lumboperitoneal shunt procedure in a case of anticoagulation therapy-resistant cerebral venous thrombosis. J Stroke Cerebrovasc Dis 2016;25:e15-e19.

68 Aaron S, Alexander M, Moorthy RK, et al. Decompressive craniectomy in cerebral venous thrombosis: a single centre experience. J Neurol Neurosurg Psychiatry 2013:84:995-1000

69 Ferro JM, Crassard I, Coutinho JM, et al. Decompressive surgery in cerebrovenous thrombosis: a multicenter registry and a systematic review of individual patient data. Stroke 2011:42:2825-31.

70 Zuurbier SM, Coutinho JM, Majoie CB, et al. Decompressive hemicraniectomy in severe cerebral venous thrombosis: a prospective case series. J Neurol 2012;259:1099-105.
71 Mokin M, Lopes DK, Binning MJ, et al. Endovascular treatment of cerebral venous thrombosis: contemporary multicenter experience. Interv Neuroradio/ 2015;21:520-6.

72 Mammen S, Keshava SN, Moses V, et al. Role of penumbra mechanical thrombectomy device in acute dural sinus thrombosis. Indian J Radiol Imaging 2017;27:82-7.

73 Vines FS, Davis DO. Clinical-radiological correlation in cerebral venous occlusive disease. Radiology 1971;98:9-22.

74 Scott JA, Pascuzzi RM, Hall PV, et al. Treatment of dural sinus thrombosis with local urokinase infusion. Case report. J Neurosurg 1988;68:284-7.

75 Barnwell SL, Nesbit GM, Clark WM. Local thrombolytic therapy for cerebrovascular disease: current Oregon Health Sciences University experience (July 1991 through April 1995). J Vasc Interv Radiol 1995;6 785-82.

76 Horowitz M, Purdy P, Unwin H, et al. Treatment of dural sinus thrombosis using selective catheterization and urokinase. Ann Neurol 1995:38:58-67.

77 Smith TP, Higashida RT, Barnwell SL, et al. Treatment of dural sinus thrombosis by urokinase infusion. AJNR Am J Neuroradiol 1994;15:801-7.

78 Kermode AG, Ives FJ, Taylor B, et al. Progressive dural venous sinus thrombosis treated with local streptokinase infusion. J Neurol Neurosurg Psychiatry 1995;58:107-8.

79 Curtin KR, Shaibani A, Resnick SA, et al. Rheolytic catheter thrombectomy, balloon angioplasty, and direct recombinant tissue plasminogen activator thrombolysis of dural sinus thrombosis with preexisting hemorrhagic infarctions. AJNR Am J Neuroradiol 2004;25:1807-11.

80 Frey JL, Muro GJ, McDougall CG, et al. Cerebral venous thrombosis: combined intrathrombus rtPA and intravenous heparin. Stroke 1999;30:489-94.

81 Soleau SW, Schmidt R, Stevens S, et al. Extensive experience with dural sinus thrombosis. Neurosurgery 2003;52:534-44.

82 Ziu $\mathrm{E}$, Haley $\mathrm{O}$, Ibrahimi $\mathrm{M}$, et al. A series of cerebral venous sinus thromboses treated with intra-arterial tPA infused over ten hours with a 0.027 -inch catheter and literature review. Cureus 2016;8:e654.

83 Kim SY, Suh JH. Direct endovascular thrombolytic therapy for dural sinus thrombosis: infusion of alteplase. AJNR Am J Neuroradiol 1997;18:639-45.

84 Jankowitz BT, Bodily LM, Jumaa $\mathrm{M}$, et al. Manual aspiration thrombectomy for cerebral venous sinus thrombosis. J Neurointerv Surg 2013;5:534-8.

85 Raychev R, Tateshima S, Rastogi S, et al. Successful treatment of extensive cerebral venous sinus thrombosis using a combined approach with Penumbra aspiration system and Solitaire FR retrieval device. J Neurointerv Surg 2014;6:e32.

86 Gariel F, Berge J, Dousset V. Neurological recovery after coma related to diffuse cerebral venous sinus thrombosis. Interest in thrombi-aspiration with Penumbra system. Interv Neuroradiol 2015;21:218-21.

87 Chen C, Wang Q, Li X, et al. Stent retriever thrombectomy combined with local thrombolytic therapy for cerebral venous sinus thrombosis: a case report. Exp Ther Med 2017;14:3961-70.

88 Froehler MT. Successful treatment of cerebral venous sinus thrombosis with the Solitaire FR thrombectomy device. J Neurointerv Surg 2013;5:e45

89 Mascitelli JR, Pain M, Zarzour HK, et al. Sinus thrombectomy for purulent cerebral venous sinus thrombosis utilizing a novel combination of the Trevo stent retriever and the Penumbra ACE aspiration catheter: the stent anchor with mobile aspiration technique. J Neurointerv Surg 2016;8:e24.

90 Taniguchi S, Harada K, Kajihara M, et al. Combined use of stent-retriever and aspiration thrombectomy for cerebral venous sinus thrombosis involving the straight sinus: a case report. Interv Neuroradio/ 2017;23:605-8.

91 Matsuda Y, Okada H, Chung J, et al. Novel balloon-and-aspiration method for cerebral venous sinus thrombosis: dental-floss technique. Neurosurg Focus 2017;42:E19.

92 Frei DH D, Bellon R, Dooley G. Mechanical balloon thromboembolectomy for the treatment of cerebral venous sinus thrombosis (CVT): a restropsective analysis of safety and efficacy in 65 consecutive patients. SNIS 8th Annual meeting.

93 Adachi $\mathrm{H}$, Mineharu Y, Ishikawa T, et al. Stenting for acute cerebral venous sinus thrombosis in the superior sagittal sinus. Interv Neuroradiol 2015;21:719-23.

94 Dashti SR, Hu YC, Yao T, et al. Mechanical thrombectomy as first-line treatment for venous sinus thrombosis: technical considerations and preliminary results using the AngioJet device. J Neurointerv Surg 2013;5:49-53.

95 Putaala J, Hiltunen S, Salonen O, et al. Recanalization and its correlation to outcome after cerebral venous thrombosis. J Neuro/ Sci 2010;292(1-2):11-15.

96 Arauz A, Vargas-González JC, Arguelles-Morales N, et al. Time to recanalisation in patients with cerebral venous thrombosis under anticoagulation therapy. J Neurol Neurosurg Psychiatry 2016;87:247-51. 